\title{
ESTERIFICATION OF PALMITIC ACID WITH METHANOL IN THE PRESENCE OF MACROPOROUS ION EXCHANGE RESIN AS CATALYST
}

\author{
AMElia QARINA YAAKOB AND SUBHASH BHATIA* \\ School of Chemical Engineering, Universiti Sains Malaysia, Engineering Campus, 14300 \\ Nibong Tebal, Penang Malaysia \\ *Email: chbhatia@eng.usm.my
}

\begin{abstract}
The esterification of palmitic acid with methanol was studied in a batch reactor using macro porous ion exchange resin Amberlyst 15 as a catalyst. Methyl palmitate was produced from the reaction between palmitic acid and methanol in the presence of catalyst. The effects of processing parameters, molar ratio of alcohol to acid M, (4-10), catalyst loading (0-10 g cat/liter), water inhibition (0-2 mol/liter), agitator speed (200$800 \mathrm{rpm})$ and reaction temperature (343-373K) were studied. The experimental kinetic data were correlated using homogenous as well as heterogeneous models (based on single as well as dual site mechanisms). The activation energy of the reaction was 11.552 $\mathrm{kJ} / \mathrm{mol}$ for forward reaction whilst $5.464 \mathrm{~kJ} / \mathrm{mol}$ for backward reaction. The experimental data fitted well with the simulated data obtained from the kinetic models.
\end{abstract}

Keywords: Palmitic Acid, Methanol, Esterification, Ion Exchange Resin, Kinetics.

\section{INTRODUCTION}

African oil palm, Elaeis guineensis, is one of the most important plants in Malaysia. It produces palm oil and palm kernel oil, which are widely used in food and oleo chemical industries for the production of fatty acids and cosmetics. Malaysia is the world's largest producer and exporters of these oils, accounting for approximately $10 \%$ of the world's oil and fat production.

About 100,000 metric tons of the natural fatty acids are consumed in the preparation of various fatty acid esters. The simple esters with lower chain alcohols (methyl-, ethyl-, npropyl-, isopropyl- and butyl esters) are used as emollients in cosmetics and other personal care products and lubricants. Organic esters are most frequently used as plasticizers, solvents, perfumery and flavor chemicals. Esters of fatty acids with more complex alcohols, such as sorbitol, ethylene glycol, diethylene glycol and polyethylene glycol are consumed in foods, personal care, paper, water treatment, metal working fluids, rolling oils and synthetic lubricants. Methyl palmitate is one type of methyl esters and being used in industry such as for biodiesel, solvents for paint, adhesives, cosmetics and toilet soap. 
Esterification is the reaction of free fatty acids with alkyl alcohol to form fatty acid esters and water as shown in the following chemical reaction:

$$
\mathrm{R}-\mathrm{COOH}+\mathrm{R}^{\prime}-\mathrm{OH} \rightarrow \mathrm{R}-\mathrm{COO}-\mathrm{R}^{\prime}+\mathrm{H}_{2} \mathrm{O}
$$

It is an endothermic reaction [1]. This process is usually carried out in the presence of acid catalysts such as $\mathrm{H}_{2} \mathrm{SO}_{4}, \mathrm{H}_{3} \mathrm{PO}_{4}$ and sulfonic acid. To shift the equilibrium of the esterification towards the desired alkyl ester, one of the reactant, usually the alcohol is fed in excess and product water is continuously removed respectively during the reaction. Generally water is eliminated chemically, physically, or by pervaporation [2].

In the present work, the kinetics of the heterogeneous esterification of palmitic acid with methanol is studied in a batch reactor using Amberlyst 15 (cation exchange resin) as a catalyst. Methyl palmitate is produced from palmitic acid and methanol via catalytic esterification represented as:

$$
\mathrm{CH}_{3}\left(\mathrm{CH}_{2}\right)_{14} \mathrm{COOH}+\mathrm{CH}_{3} \mathrm{OH} \rightarrow \mathrm{CH}_{3}\left(\mathrm{CH}_{2}\right)_{14} \mathrm{COOCH}_{3}+\mathrm{H}_{2} \mathrm{O}
$$

$$
\text { Palmitic acid Methanol Methyl palmitate Water }
$$

The use of a solid ion exchange resin as catalyst has a number of advantages [3]. These are

i. the catalyst can be easily removed from the reaction products by decantation or filtration.

ii. continuous operation in columns is possible.

iii. the purity of the products is higher since side reactions can be completely eliminated or are less significant.

iv. it is possible to isolate the reaction intermediates

v. ion exchange resin can discriminate between small and large molecules.

There are many solid catalysts reported in the literature for esterification reactions [46]. Cation exchange resin is the most commonly used solid acid catalyst in organic reactions [5]. Ion exchange resins have been used in esterification [7] and hydrolysis of methyl acetate in a catalytic distillation column [8].

The objective of the present study is to find the applicability of the cation exchange macro porous resin as catalyst for the fatty acid esterification and to study the effects of important processing parameters for esterification process. The kinetics of esterification of palmitic acid with methanol in the liquid phase using cation exchange macro porous resin Amberlyst 15 is studied. The reaction rates are evaluated using homogeneous and heterogeneous models and experimental data are compared with the simulated data. 


\section{MATERIALS AND METHOD}

\subsection{MATERIALS}

\subsubsection{Palmitic acid}

Palmitic acid was obtained from Acidchem International Sdn.Bhd. Penang, Malaysia. The purity of palmitic acid used in the experiments was $98.9 \%$.

\subsubsection{Catalyst}

Amberlyst 15 was purchased from Acros Organics New Jersey, USA. The properties of Amberlyst 15 are presented in Table 1.

Table 1: Typical Physical and Chemical Properties of Amberlyst 15 Catalyst

\begin{tabular}{cc}
\hline Properties & Amberlyst 15 \\
\hline Physical Form & Opaque, spherical bead \\
Ionic form & $\mathrm{H}^{+}$ \\
Concentration of Acid Sites (meq H+/(g.cat)) & 4.9 \\
Moisture content (mass\%) & 53 \\
Particle size (mm) & $0.35-1.20$ \\
Porosity (mL/g) & 0.30 \\
Average Pore Diameter (nm) & 25.0 \\
Surface area (m $\left.{ }^{2} / \mathrm{g}\right)$ & 45 \\
Maximum Temperature $\left({ }^{0} \mathrm{C}\right)$ & 120 \\
Crosslinking Density $(\% \mathrm{DVB})$ & 20 \\
\hline
\end{tabular}

\section{CATALYST PREPARATION}

The fresh resin was washed with deionized water and kept at $348 \mathrm{~K}$ in a vacuum oven before used in an experimental run.

\subsection{EXPERIMENTAL SETUP}

A 4-neck Pyrex flask of $500 \mathrm{ml}$ capacity was used as the reactor. The volume of the mixture used for each reaction was $300 \mathrm{ml}$. The condenser was connected to the central opening; the two side openings were used to measure the reaction temperature using a thermocouple (K type) and to withdraw the samples during the reaction respectively. One opening was used for feeding alcohol.

An oil bath with digital temperature controller was used to supply heat to the system. Silicon oil was used in the bath since it can be heated up to high temperature (up to 300 
$\left.{ }^{\circ} \mathrm{C}\right)$. The oil bath was equipped with a heater, a thermocouple to indicate the temperature in the bath, a temperature controller and a circulator. The circulator was used to circulate the oil continuously and to keep the temperature in the bath uniform. The temperature was controlled with the accuracy of $\pm 1{ }^{\circ} \mathrm{C}$.

A magnetic stirring plate was placed right at the bottom of the oil bath to stir the reaction mixture continuously. A glass coil condenser was used to cool and condense back the reaction mixture vapors during the reaction. The reaction temperature was varied from $70{ }^{\circ} \mathrm{C}$ to $100{ }^{\circ} \mathrm{C}$, well above the boiling point of methanol $\left(64.7^{\circ} \mathrm{C}\right)$. The average boiling point of the reaction mixture was $65^{\circ} \mathrm{C}$ to $70{ }^{\circ} \mathrm{C}$ depending on the molar ratio of reactants used. A thermocouple and a temperature controller were used to monitor the reaction temperature.

\subsection{PROCEDURE}

The esterification of palmitic acid with methanol was carried out in a batch reactor system. The data were obtained to study the kinetics of the reaction and to evaluate the kinetic parameters of the esterification process. A pre-mixed method was opted in order to study the behavior of the heterogeneous catalyst. Blank experiment was carried out in the batch reactor without catalyst to check any conversion during esterification.

The palmitic acid and catalyst were mixed in the flask of the reactor. Pre-heated alcohol $\left(50{ }^{\circ} \mathrm{C}\right)$ was added once the desired temperature was reached. This time was considered as the beginning of the experiment. It took about 30 minute to get steady state temperature. The reactant temperature was maintained constant $\left( \pm 0.1{ }^{\circ} \mathrm{C}\right)$. Two $\mathrm{m} l$ sample of the reaction mixture was drawn from the flask every 20 minutes interval using a sampling tube and were immediately cooled to $0{ }^{\circ} \mathrm{C}$ in order to stop the reaction. The sample was titrated to determine the amount of fatty acid that remained unreacted.

\section{RESULTS AND DISCUSSION}

\subsection{PROCESS STUDIES}

\subsubsection{Effect of Important Processing Variables}

Experiments were conducted by various processing variables such as reaction temperature, alcohol to acid ratio, catalyst loading, speed of agitation and the presence of water. Table 2 shows the variation of these variables with its range.

\section{(a) Effect of Reaction Temperature}

In order to investigate the effect of temperature, the reaction temperature was adjusted from 343 to $373 \mathrm{~K}$. The esterification process was carried out at the methanol to palmitic acid molar ratio of $4(\mathrm{M}=4)$ and the catalyst loading of $5 \mathrm{~g}$ cat/liter. 
Table 2: Range of processing variables over esterification of palmitic acid with methanol using Amberlyst 15.

\begin{tabular}{cc}
\hline Processing Parameters & Range \\
\hline Temperature & 343 to $373 \mathrm{~K}$ \\
Methanol/Palmitic Acid & 4 to 10 \\
Catalyst Loading & 0 to $10 \mathrm{~g}$ cat/liter \\
Water Inhibition & 0 to $2 \mathrm{~mol} / \mathrm{liter}$ \\
Agitation speed & 200 to $700 \mathrm{rpm}$ \\
\hline
\end{tabular}

Figure 1 shows the effect of reaction temperature on the conversion of palmitic acid to methyl palmitate. Since the esterification of fatty acid with alcohol is an endothermic reaction, therefore with the increase of temperature, the conversion of fatty acid increased [9]. Similar trends were reported in the literature [1, 10]. It can be seen from the figure that the effect of temperature on the rate of methyl palmitate production is significant. The reaction rate increased sharply with increasing temperature. The reaction temperature was limited to $373 \mathrm{~K}$ due to thermal stability of ion-exchange resin.

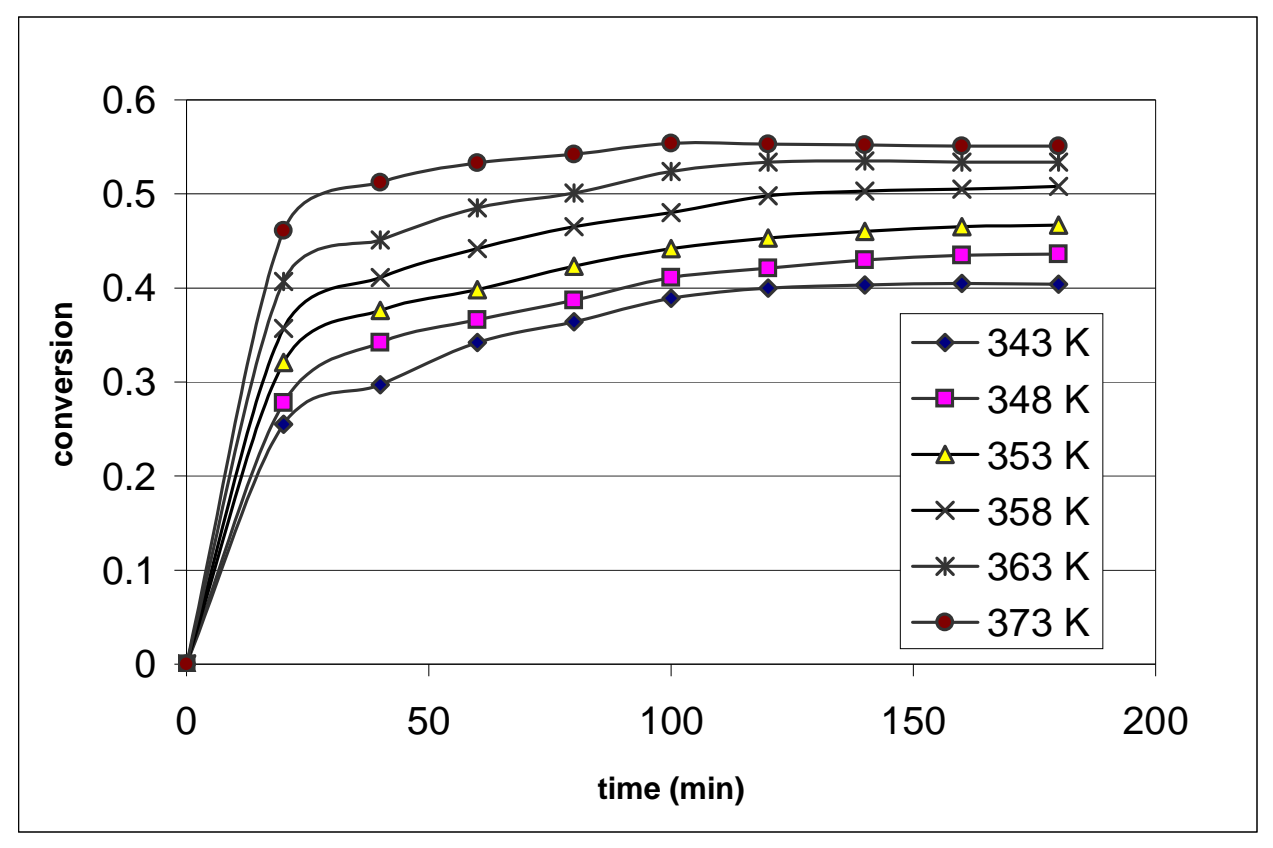

Fig. 1: Effect of temperature on the conversion of palmitic acid to methyl palmitate rate at the operating conditions of $\mathrm{M}=4$ and catalyst loading of $5 \mathrm{~g}$ cat/liter. 


\section{(b) Effect of Molar Ratio}

Methanol was taken in far excess over palmitic acid to shift the equilibrium towards the formation of ester. This method was chosen because it was not easy to remove water, since the boiling point of methanol $\left(64.5^{\circ} \mathrm{C}\right)$ was much lower than the boiling point of water $\left(100{ }^{\circ} \mathrm{C}\right)$. The molar ratio of palmitic acid to methanol used was $1: 4,1: 6,1: 8$ and 1:10. The process was carried out at constant temperature of $343 \mathrm{~K}$ and catalyst loading of $5 \mathrm{~g}$ cat/liter.

Figure 2 shows the effect of molar ratio on the conversion of palmitic acid to methyl palmitate. It is clear from the figure that the higher reaction rates and higher equilibrium conversion were achieved when the alcohol was in excess. The concentration of methanol influenced the reaction rate and conversion. As the molar ratio of methanol to palmitic acid increased, the conversion of palmitic acid increased due to excess concentration of methanol.

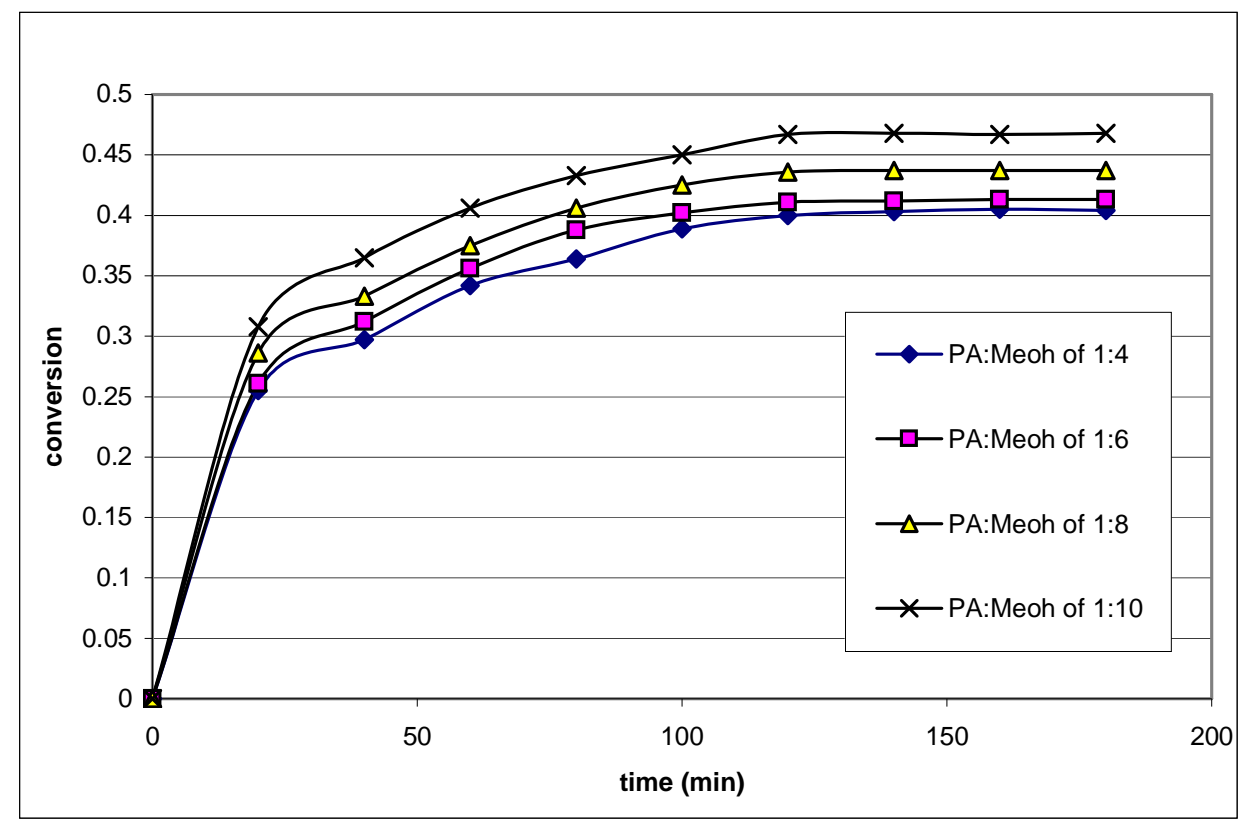

Fig. 2: Effect of molar ratio on the conversion of palmitic acid to methyl palmitate at temperature $343 \mathrm{~K}$ and catalyst loading of 5 gcat/liter.

\section{(c) Effect of Catalyst Loading}

Figure 3 shows the effect of catalyst loading (0-10 g cat/liter) on the conversion of palmitic acid at a temperature of $343 \mathrm{~K}$ and methanol to palmitic acid molar ratio of 4 . Figure shows that with the increase of catalyst loading from $2 \mathrm{~g}$ cat/liter to $5 \mathrm{~g}$ cat/liter, the rate of reaction was increased. It was also found that at $10 \mathrm{~g}$ cat/liter catalyst loading, the conversion rate of palmitic acid to methyl palmitate was almost similar to that obtained at $5 \mathrm{~g}$ cat/liter catalyst loading. This was because at $10 \mathrm{gcat} /$ liter, the reactor was no more operated as a liquid phase batch reactor but rather as a slurry phase reactor. In slurry reactor, both the external and internal mass transfer resistance could be present. These 
resistances affected the conversion and therefore the conversion did not increase with the increase of catalyst loading to $10 \mathrm{~g}$ cat/liter. This type of solid acid catalyzed esterification is a typical solid-liquid slurry reaction at higher loading of catalyst.

\section{(d) Effect of Agitation Speed}

The experiments were carried out at different speeds, varied from 200 to $700 \mathrm{rpm}$. It is important to obtain intrinsic kinetics that the experiments were conducted under vigorous stirring to avoid mass transfer effects especially film diffusion. The experiments were conducted at $\mathrm{M}=4$, reaction temperature of $343 \mathrm{~K}$ and catalyst loading $5 \mathrm{~g}$ cat/liter.

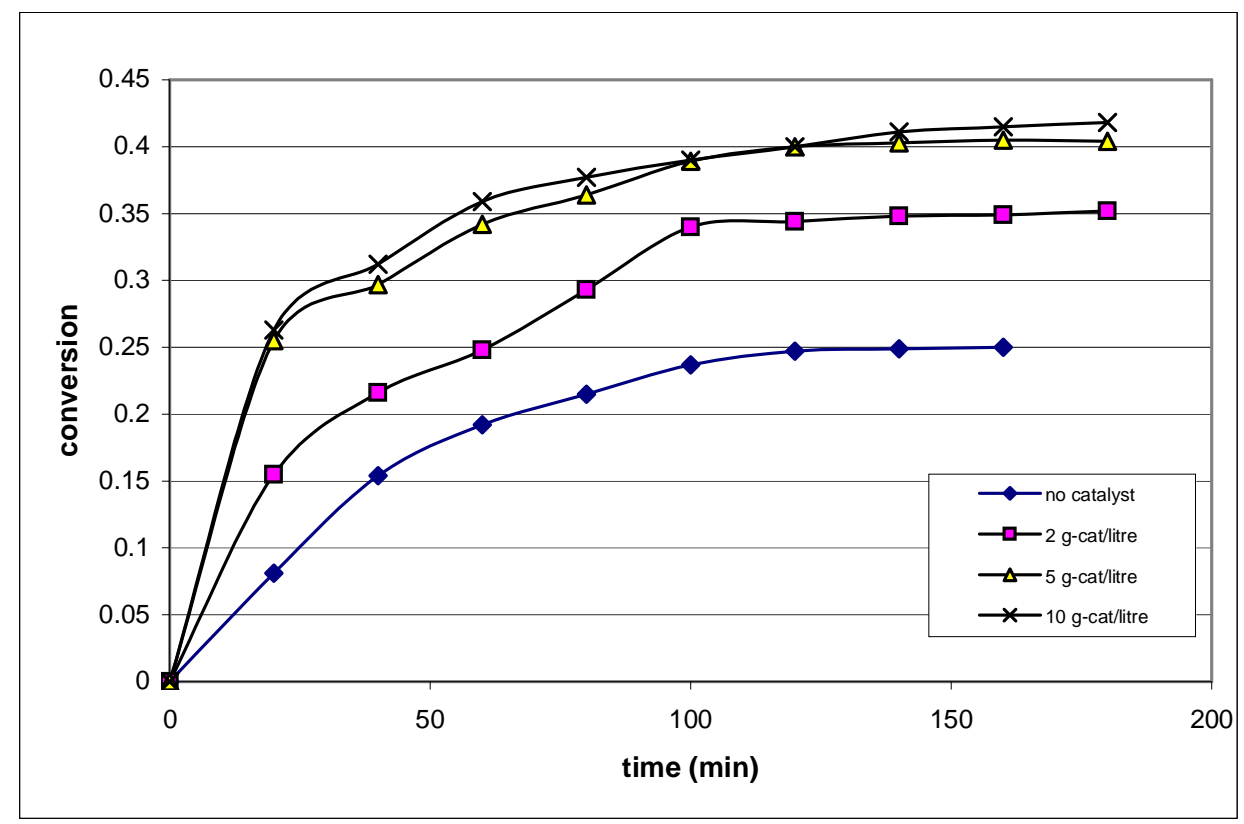

Fig. 3: Effect of catalyst loading on the conversion of palmitic acid to methyl palmitate at temperature $343 \mathrm{~K}$ and $\mathrm{M}=4$.

Figure 4 shows that the conversion of palmitic acid was unaffected by the agitation speed in the range of 400-800 rpm but between 200 and $400 \mathrm{rpm}$, the speed affected the conversion rate of palmitic acid. At higher stirrer speeds, there was no noticeable effect on conversion indicating that diffusion was not the controlling mechanism in the rate of reaction. This was inline with the findings of Chakrabarti and Sharma [5] where they reported that the external diffusion doesn't generally control the overall rate in ion exchange resin catalyzed process unless the viscosity of the reactant mixture is very high or the speed of agitation is very low. 


\section{(e) Effect of Water Inhibition}

The effect of water inhibition on the conversion of palmitic acid was studied by varying the volume of water in the range of 0.3 to $2 \mathrm{~mol} /$ liter of total reactant mixture. The reaction temperature of $343 \mathrm{~K}$, methanol to palmitic acid molar ratio of 4 and catalyst loading of $5 \mathrm{~g}$ cat/liter were kept constant in all runs.

The effect of water inhibition in the feed on the esterification of palmitic acid is shown in Figure 5. As the water concentration in the feed was increased, the conversion dropped. It was due to the reversibility of the reaction where some of the methyl palmitate was hydrolyzed to palmitic acid. Similar effect of water inhibition was reported for carboxylic acids esterification studies [1]. Water molecules can occupy the active sites of ion exchange resin, Amberlyst 15, therefore the conversion dropped due to a decrease in active sites available for the reaction.

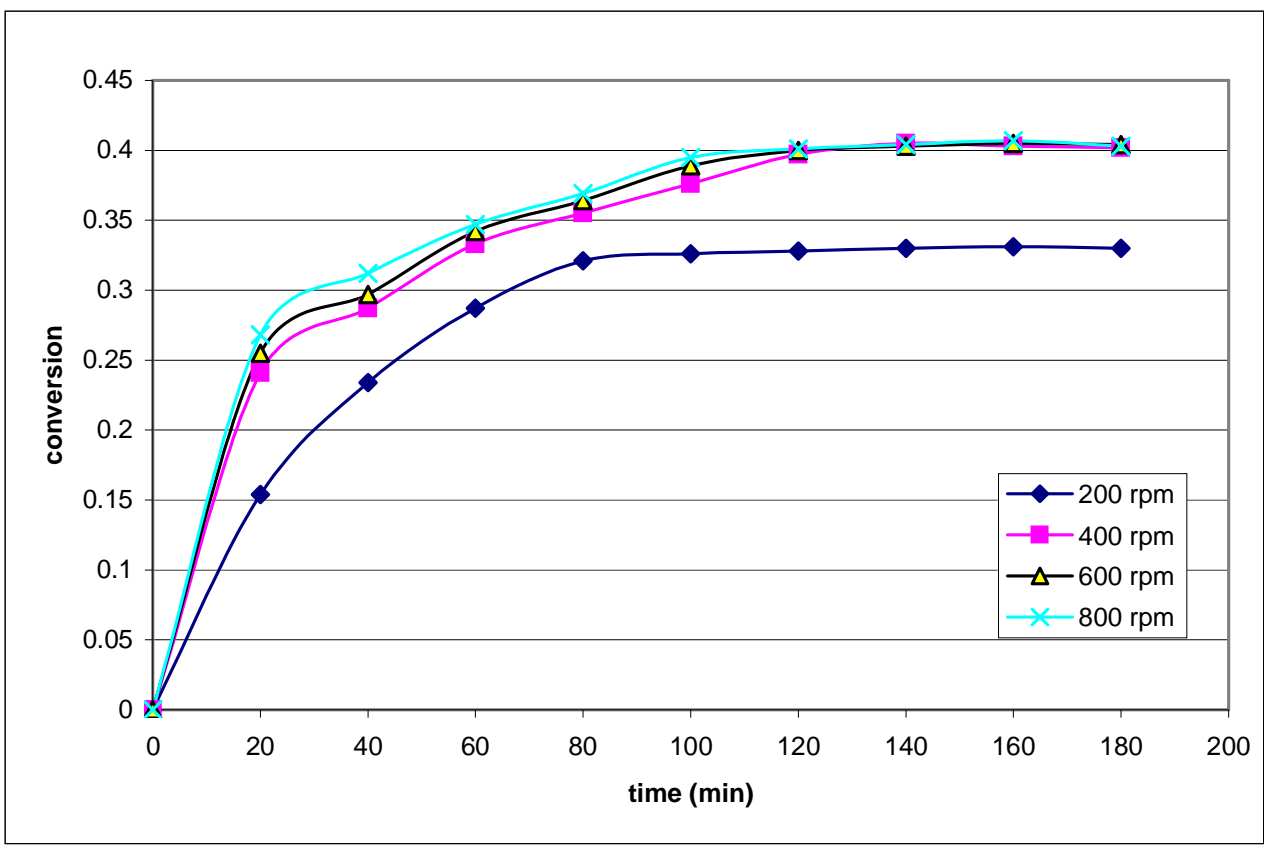

Fig. 4: Effect of agitation on the conversion of palmitic acid to methyl palmitate at temperature $343 \mathrm{~K}, \mathrm{M}=4$ and catalyst loading of $5 \mathrm{~g}$ cat/liter. 


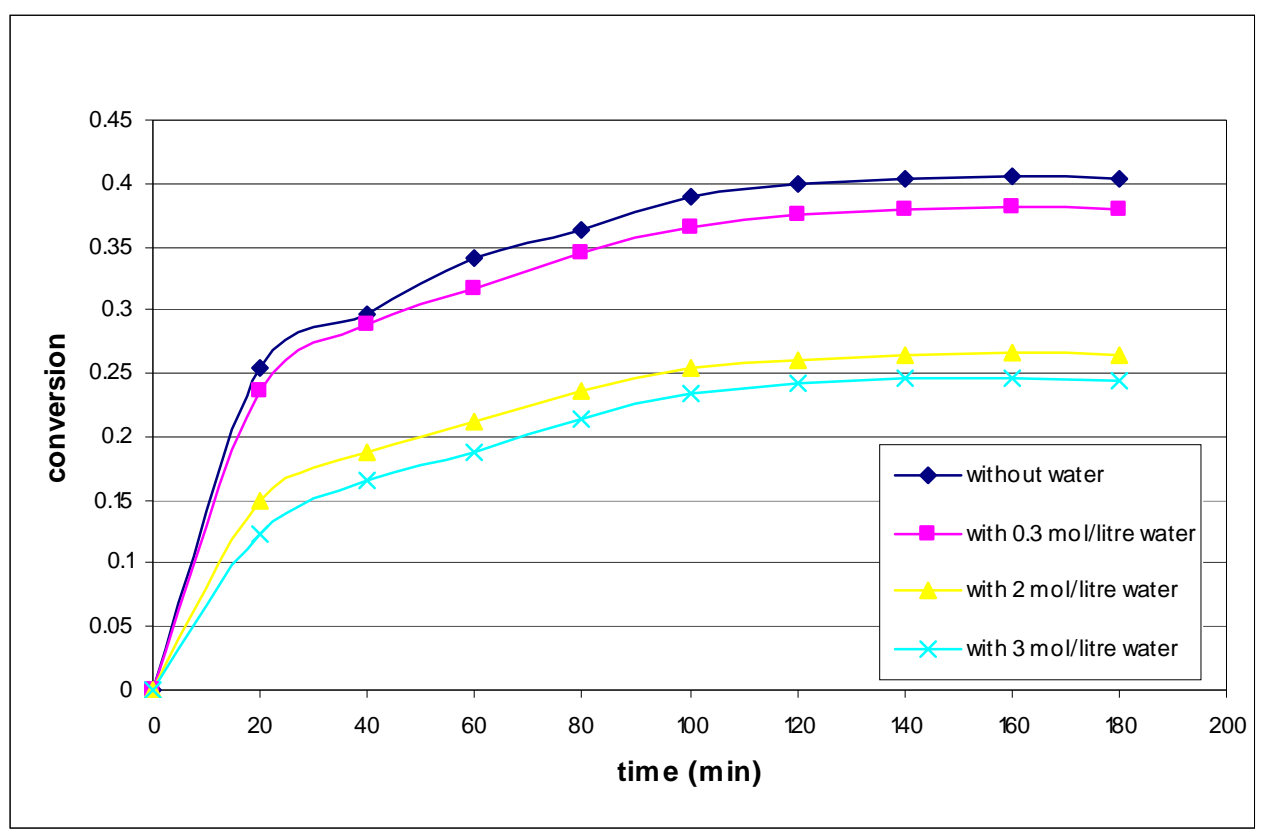

Fig. 5 Effect of water inhibition in the feed on the conversion of palmitic acid to methyl palmitate at temperature $343 \mathrm{~K}, \mathrm{M}=4$ and catalyst loading of $5 \mathrm{~g}$ cat/liter.

\subsubsection{Ion exchange resin reusability}

The reusability of ion exchange resin was also studied in order to check the deactivation of the catalyst during reaction. The reusability test was conducted at temperature $343 \mathrm{~K}$, methanol to palmitic acid molar ratio of 4 and catalyst loading of $5 \mathrm{~g}$ cat/liter. The reused resin was washed with deionized water and kept in the oven overnight at $348 \mathrm{~K}$ to remove the moisture completely. Figure 6 shows the conversion of palmitic acid with fresh and the reused catalysts. No sign of deactivation was observed for the used catalyst, so the resin could be used repeatedly after suitable treatment. However, fresh resin was used for each run to ensure the consistency of experimental conditions. 


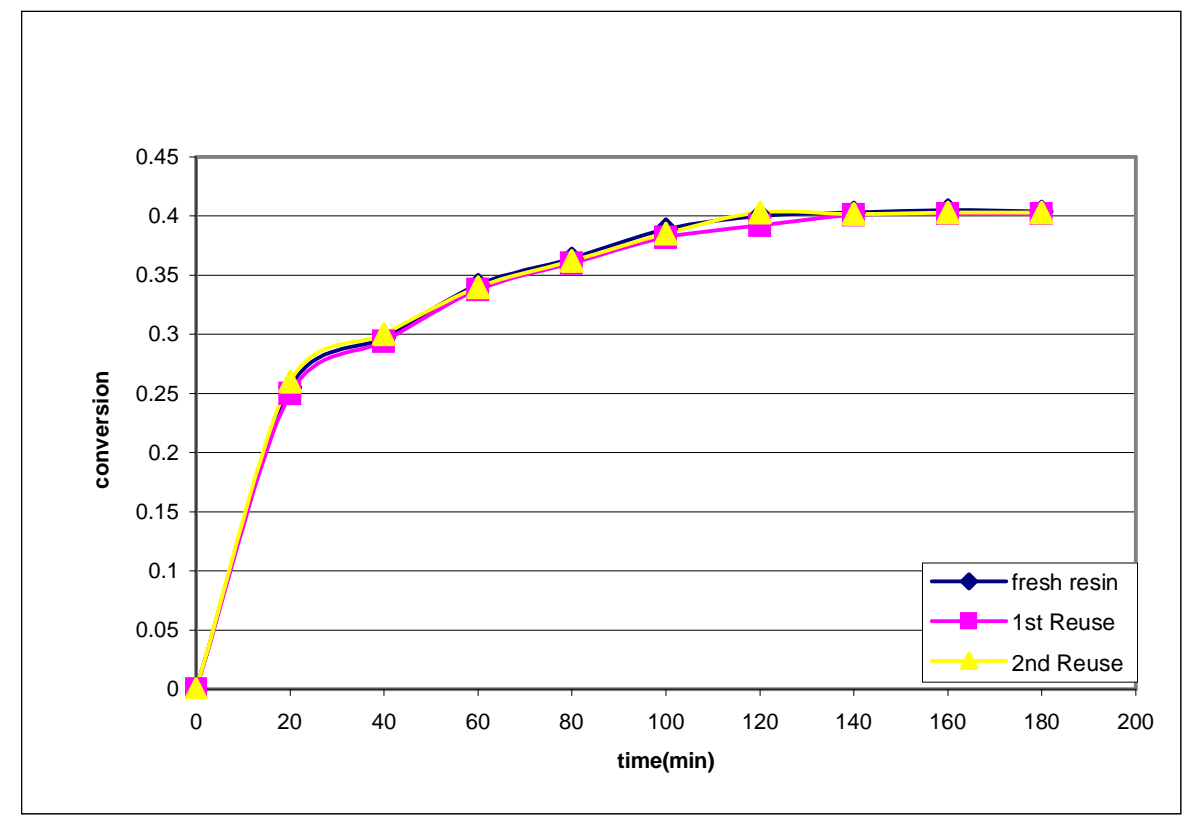

Fig. 6: Catalyst reusability test at temperature $343 \mathrm{~K}, \mathrm{M}=4$ and catalyst loading of 5 gcat/litre.

\section{KINETICS AND MODELLING}

The kinetic parameters for the esterification of palmitic acid were determined using homogeneous and heterogeneous models. The kinetics was used for the prediction of conversion over a wide range of reaction conditions. The esterification between fatty acid (A) and alcohol (B) was treated as an elementary second order reversible reaction and is represented as:

$$
A+B \Leftrightarrow E+W
$$

Homogeneous and heterogeneous models were used for comparison of kinetic parameters obtained in the present study.

\subsection{HOMOGENEOUS REACTION KINETICS}

When both external and internal mass transfer resistances are absent, the kinetics of the reaction can be expressed using power law model [10]. The conversion of fatty acid ester was determined by titration during the reaction at different interval of time in a batch reactor. Equation (4) expresses the rate equation of the elementary second order reversible reaction for batch system [11].

$$
\operatorname{In}\left[\left(\frac{1+M+a_{2}-2 a_{1} X_{A}}{1+M-a_{2}+2 a_{1} X_{A}}\right)\left(\frac{1+M-a_{2}}{1+M+a_{2}}\right)\right]=\left(\frac{a_{2}}{a_{1}}\right)\left(k_{1} C_{A O} t\right)
$$


The palmitic acid conversion at different reaction temperature is summarized in Table 3. The experiments were conducted at different temperature by keeping the molar ratio of reactants $(\mathrm{M}=4)$ and catalyst loading (5 g cat/liter) constant. The conversion value obtained at the end of 3 hours from the start of the reaction is taken as the equilibrium value.

Table 3: Conversion of palmitic acid at different reaction temperatures

\begin{tabular}{cc}
\hline Temperature $(\mathrm{K})$ & Conversion $\left(\mathrm{X}_{\mathrm{A}}\right)$ \\
\hline 343 & 0.404 \\
348 & 0.436 \\
353 & 0.467 \\
358 & 0.508 \\
363 & 0.534 \\
373 & 0.551 \\
\hline
\end{tabular}

Figure 7 shows the plot of the left hand side term of the equation (4) against reaction time, $t$. All the experimental data were found to be in excellent agreement with Eq. (4). The forward rate constant $k_{1}$ at various temperatures (343-373 K) was determined from the slope of straight line of Fig. 7. The backward reaction rate constant, $\mathrm{k}_{2}$ was obtained from Eq. (5).

$$
\mathrm{K}_{\mathrm{eq}}=\frac{k_{1}}{k_{2}}
$$

Table 4 presents the values of rate constants $\mathrm{k}_{1}$ and $\mathrm{k}_{2}$ at different temperatures. The activation energy of the forward reaction was estimated as $11.552 \mathrm{~kJ} / \mathrm{mol}$ whereas the activation energy for backward reaction was $5.464 \mathrm{~kJ} / \mathrm{mol}$. The relationship of rate constants in terms of activation energy and pre-exponential factor is given by Eq.(6) and Eq. (7), respectively.

$$
\begin{aligned}
& k_{1}=3258 \exp \left(\frac{-1389.5}{\mathrm{~T}}\right) \\
& k_{2}=3167 \exp \left(\frac{-657.29}{\mathrm{~T}}\right)
\end{aligned}
$$




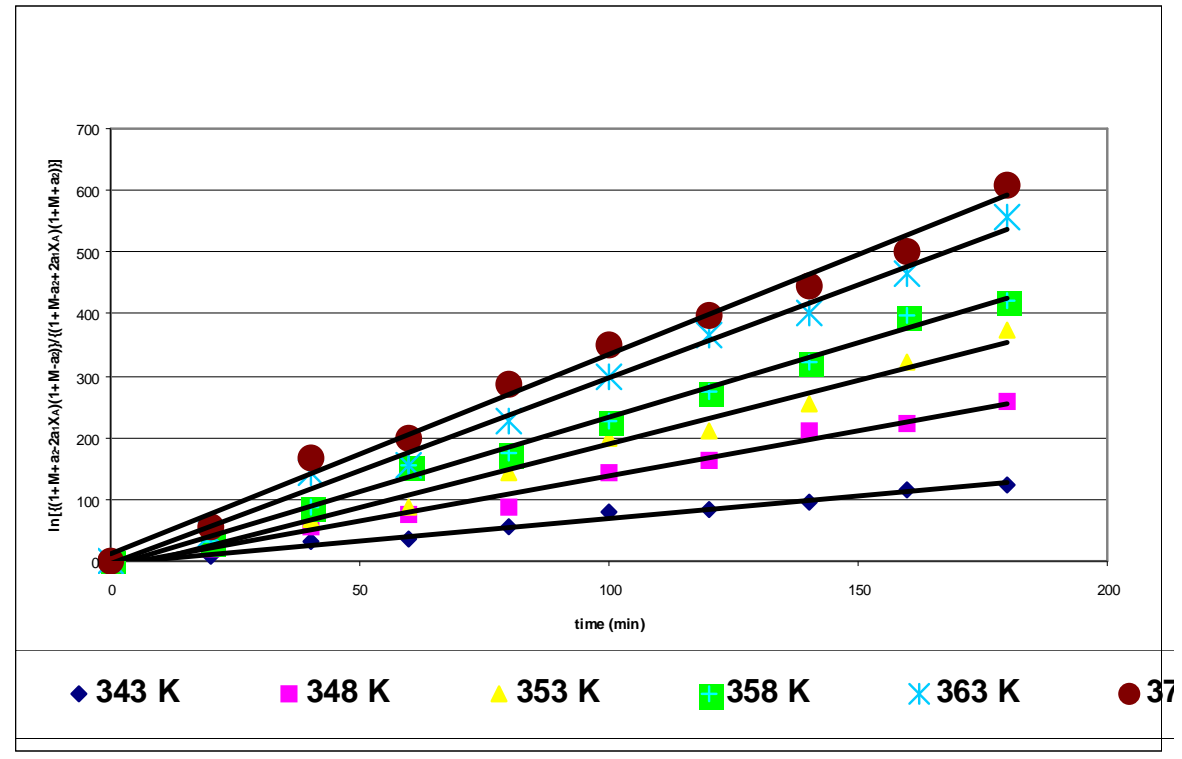

Fig. 7: Second order reaction model plot for calculation of forward rate constant $k$, at $\mathrm{M}=4$ and catalyst loading $=5 \mathrm{~g}$ cat $/$ liter.

Figure 8 shows plot of experimental rates $\left(\mathrm{r}_{\mathrm{exp}}\right)^{\prime}$ versus calculated rates $\left(\mathrm{r}_{\text {calc }}\right)$ 'obtained from the rate equation. The calculated and experimentally measured values of rates for all run of the experiments were in good agreement.

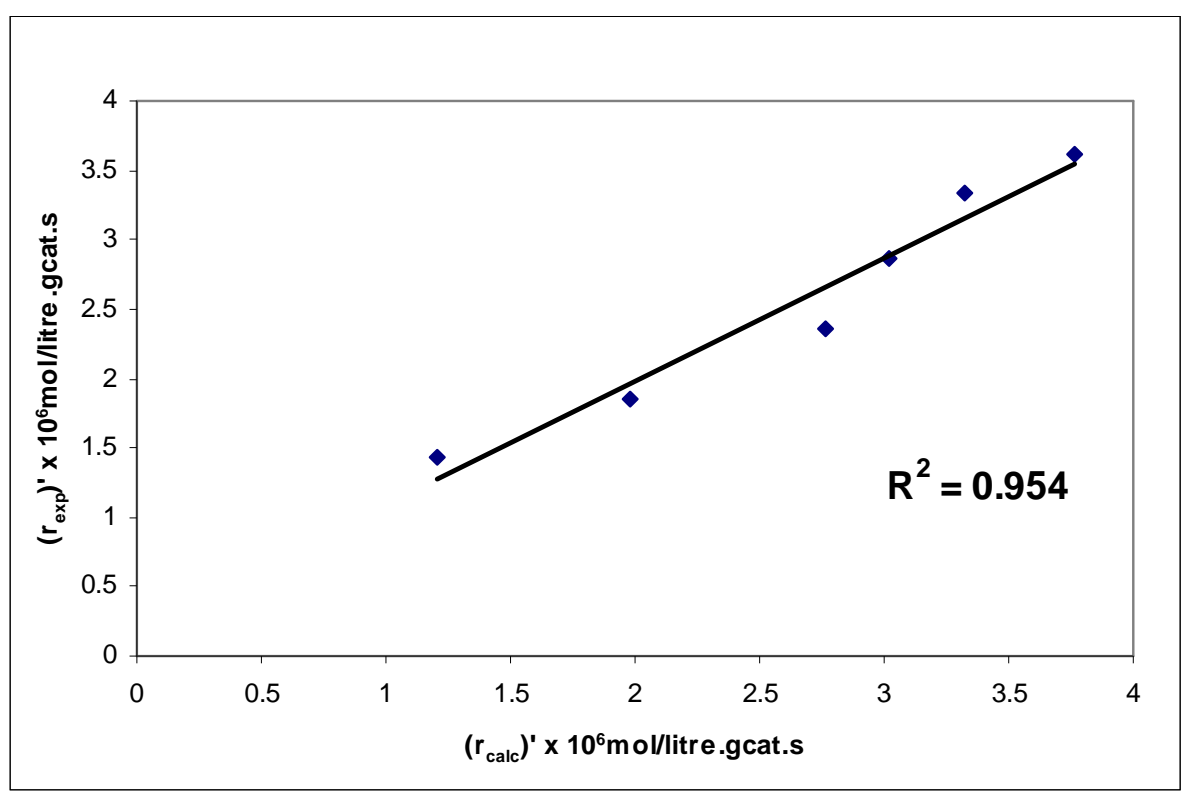

Fig. 8: Plot for experimental $\left(\mathrm{r}_{\text {exp }}\right)^{\prime}$ and calculated reaction rates $\left(\mathrm{r}_{\text {calc }}\right)^{\prime}$ at $M=4$, catalyst loading $=5 \mathrm{~g}$ cat $/$ liter using power law model equation. 


\subsection{HETEROGENEOUS REACTION KINETICS}

Since the reaction involves more than one phase; catalyst is a solid and the reactants and products are in liquid form, the reaction is treated as heterogeneous catalytic reaction. Heterogeneous model analysis and results can be compared with the homogeneous model results. The heterogeneous rate of reaction is defined as:

$$
\left(r_{\exp }\right)^{\prime}=\frac{\text { Concentration of methyl palmitate }(\mathrm{mol} / \text { liter })}{(\text { Weight of catalyst }(\mathrm{g}) \mathrm{X} \text { time }(\mathrm{s}))}
$$

Table 5 summarizes the rate of reaction, $\left(\mathrm{r}_{\text {exp }}\right)^{\prime}$ obtained after 3 hours from the start of the reaction. The Langmuir Hinshelwood Hougen Watson (LHHW) equation for surface reaction control for esterification of palmitic acid with methanol is given by Eq. (9) [1]:

$$
\left(r_{\text {exp }}\right)^{\prime}=\left(-r_{s}\right)^{\prime}=k_{s}\left[\frac{\mathrm{K}_{\mathrm{A}} \mathrm{K}_{\mathrm{B}} \mathrm{C}_{\mathrm{AO}}^{2}\left(1-\mathrm{X}_{\mathrm{A}}\right)\left(\mathrm{M}-\mathrm{X}_{\mathrm{A}}\right)-\left[\frac{\mathrm{K}_{\mathrm{E}} \mathrm{K}_{\mathrm{W}}\left(\mathrm{C}_{\mathrm{AO}} \mathrm{X}_{\mathrm{A}}\right)^{2}}{\mathrm{~K}_{\mathrm{S}}}\right]}{\left\{1+\mathrm{K}_{\mathrm{A}} \mathrm{C}_{\mathrm{AO}}\left(1-\mathrm{X}_{\mathrm{A}}\right)+\mathrm{K}_{\mathrm{B}} \mathrm{C}_{\mathrm{AO}}\left(\mathrm{M}-\mathrm{X}_{\mathrm{A}}\right)+\mathrm{C}_{\mathrm{AO}} \mathrm{X}_{\mathrm{A}}\left(\mathrm{K}_{\mathrm{E}}+\mathrm{K}_{\mathrm{W}}\right)\right\}^{2}}\right]
$$

Table 5: Experimental rate of reaction $\left(\mathrm{r}_{\exp }\right)^{\prime}$ in heterogeneous system

\begin{tabular}{cc}
\hline Temperature $(\mathrm{K})$ & $\begin{array}{c}\text { Experimental Reaction Rates }-\left(\mathrm{r}_{\text {exp }}\right)^{\prime \prime}{ }^{\prime}, \mathrm{x} \\
10^{6} \text { mol/liter'gcat's }\end{array}$ \\
\hline 343 & 1.44 \\
348 & 1.85 \\
353 & 2.36 \\
358 & 2.87 \\
363 & 3.34 \\
373 & 3.61 \\
\hline
\end{tabular}

The value of $k_{s}, \mathrm{~K}_{\mathrm{S}}, \mathrm{K}_{\mathrm{A}}, \mathrm{K}_{\mathrm{B}}, \mathrm{K}_{\mathrm{E}}$, and $\mathrm{K}_{\mathrm{W}}$ were determined using Non Linear Least Square Method $[12,13]$ by minimizing the sum of squared differences of the experimental reaction rate and calculated reaction rate from Eq. (10) [12].

$$
s^{2}=\sum \frac{\left(\left(r_{\text {exp }}\right)^{\prime}-\left(r_{\text {cal }}\right)^{\prime}\right)^{2}}{\mathrm{~N}-\mathrm{P}-1}
$$


where $N$ is a number of experimental data $(=22)$ and $P$ is a number of parameters to be determined $(=5)$

The values of $k_{s}, \mathrm{~K}_{\mathrm{S}}, \mathrm{K}_{\mathrm{A}}, \mathrm{K}_{\mathrm{B}}, \mathrm{K}_{\mathrm{E}}$ and $\mathrm{K}_{\mathrm{W}}$ were determined by POLYMATH software [13] and are summarized in Table 6 and Table 7, respectively. The pre-exponential factor, surface reaction constant and adsorption enthalpies are summarized in Table 8. The activation energy calculated from the heterogeneous model was $59.87 \mathrm{~kJ} / \mathrm{mol}$ and was higher than the activation energy obtained from the homogeneous model. The adsorption enthalpies were negative because the adsorption is an exothermic process.

Table 6: Surface reaction rate constant, $k_{\mathrm{s}}$ and equilibrium constants, $\mathrm{K}_{\mathrm{s}}$ at different temperatures

\begin{tabular}{ccc}
\hline Temperature $(\mathrm{K})$ & $\begin{array}{c}\text { Surface reaction rate constant, } \\
k_{\mathrm{s}}(\mathrm{g} \text { cat/liter mol } \mathrm{s})\end{array}$ & $\begin{array}{c}\text { Surface equilibrium } \\
\text { constant, } \mathrm{K}_{\mathrm{s}}\end{array}$ \\
\hline 343 & 0.437 & 1.944 \\
348 & 0.576 & 1.972 \\
353 & 0.654 & 2.000 \\
358 & 0.876 & 2.029 \\
363 & 1.756 & 2.057 \\
373 & 1.954 & 2.114 \\
\hline
\end{tabular}

Table 7: Adsorption equilibrium constant at different reaction temperatures obtained for model Eq. (9)

\begin{tabular}{ccccc}
\hline \multirow{2}{*}{$\begin{array}{c}\text { Temperature } \\
(K)\end{array}$} & \multicolumn{4}{c}{ Adsorption equilibrium constant (liter/mol) } \\
\cline { 2 - 5 }$K_{A}$ & $K_{B}$ & $K_{E}$ & $K_{W}$ \\
\hline 343 & $5.71 \times 10^{-2}$ & $5.46 \times 10^{-1}$ & $6.03 \times 10^{-1}$ & $6.03 \times 10^{-1}$ \\
348 & $4.33 \times 10^{-2}$ & $9.65 \times 10^{-2}$ & $5.71 \times 10^{-2}$ & $5.51 \times 10^{-2}$ \\
353 & $7.87 \times 10^{-3}$ & $3.54 \times 10^{-2}$ & $7.54 \times 10^{-3}$ & $2.35 \times 10^{-2}$ \\
358 & $5.23 \times 10^{-3}$ & $7.43 \times 10^{-3}$ & $1.98 \times 10^{-3}$ & $8.11 \times 10^{-3}$ \\
363 & $2.87 \times 10^{-4}$ & $5.32 \times 10^{-3}$ & $5.41 \times 10^{-4}$ & $3.75 \times 10^{-3}$ \\
373 & $5.21 \times 10^{-5}$ & $6.87 \times 10^{-4}$ & $1.23 \times 10^{-4}$ & $5.51 \times 10^{-4}$ \\
\hline
\end{tabular}


Figure 9 shows the plot of experimental rates $\left(r_{\text {exp }}\right)^{\prime}$ versus calculated rates $\left(r_{\text {calc }}\right)^{\prime}$. There was an excellent agreement between the calculated and experimentally measured values of rates for all the experiments.

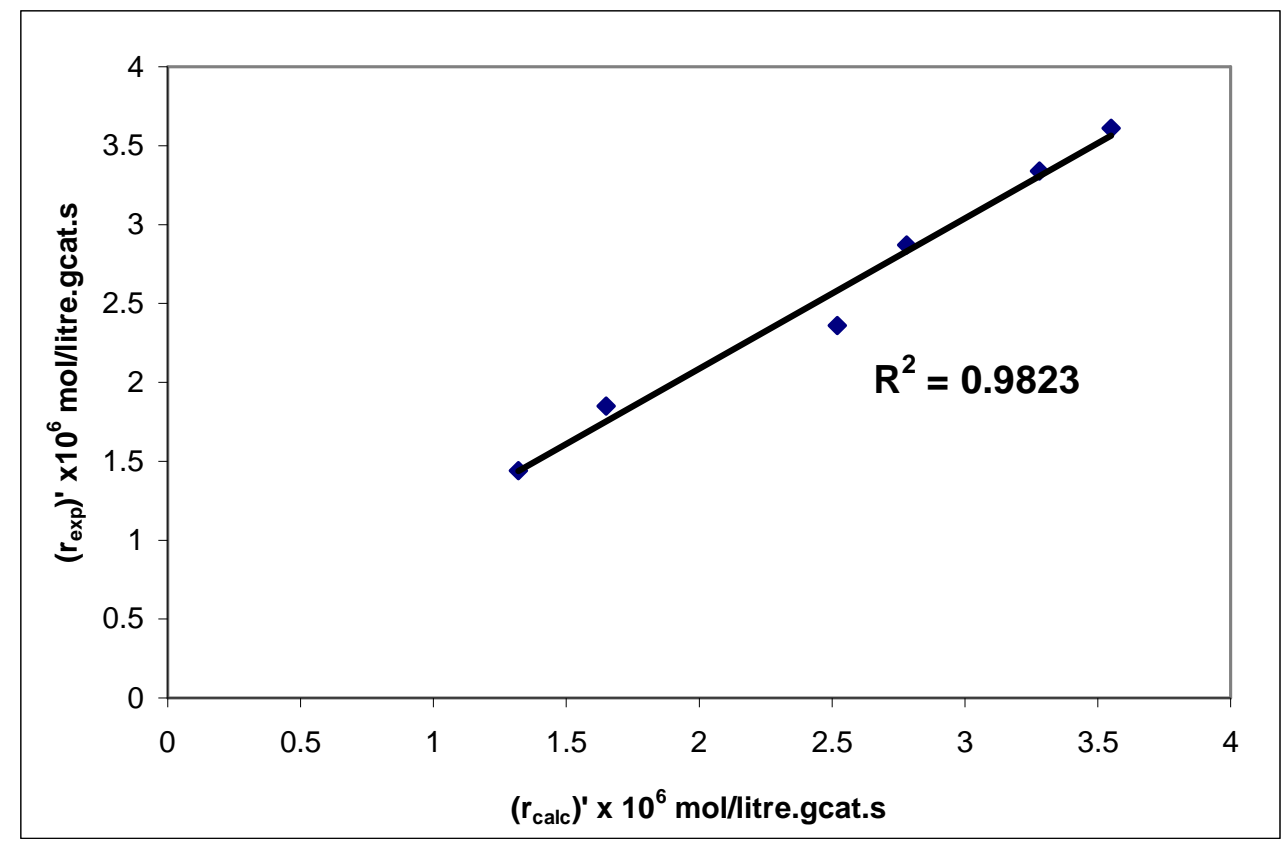

Fig. 9: Plot for experimental and calculated reaction rates at $M=4$, catalyst loading $=5$ g-cat/liter using LHHW model equation.

\section{CONCLUSIONS}

The esterification of palmitic acid with methanol in the presence of macro porous ion exchange resin as catalyst was performed. The reaction rate increased with an increase in reaction temperature (343-373K), increase in the molar ratio of palmitic acid to methanol (4-10) and with an increase of catalyst loading (0-10 g/liter). The reaction rates were unaffected by the agitation speed in the range of 400-800 rpm but between $200-400 \mathrm{rpm}$ the speed affected the conversion of palmitic acid showing the presence of film diffusion. The conversion of palmitic acid was dropped in the presence of water $(0-2 \mathrm{~mol} / \mathrm{liter})$ due to inhibition of water. Amberlyst 15 was found to be an effective catalyst for the reaction between palmitic acid and methanol. Although sulfuric acid is cheaper than resin as a catalyst, but resin can be recycled and suitable for esterification process due to various advantages over the homogeneous catalyst. The LHHW heterogeneous model could be applied for representing esterification kinetics for the formation of methyl palmitate. These models are useful in the rational design of reactors for the production of ester in oleochemical industries in Malaysia. 


\section{NOMENCLATURE}

\begin{tabular}{|c|c|}
\hline A & Fatty acid \\
\hline$a_{1}$ & $\left(\mathrm{I}-\mathrm{K}_{\mathrm{eq}}^{-1}\right)$ \\
\hline $\mathrm{a}_{2}$ & {$\left[(M+1)^{2}-4 a_{1} M\right]^{1 / 2}$} \\
\hline B & Alcohol \\
\hline $\mathrm{C}$ & Ester \\
\hline $\mathrm{C}_{\mathrm{AO}}$ & Initial concentration of fatty acid $\left(\mathrm{mol} \mathrm{L}^{-1}\right)$ \\
\hline $\mathrm{C}_{\mathrm{A}}$ & Concentration of fatty acid (mol/liter) at any time, $\mathrm{t}$ \\
\hline $\mathrm{D}$ & Water \\
\hline $\mathrm{K}_{\mathrm{eq}}$ & Equilibrium rate constant $=\mathrm{k}_{1} / \mathrm{k}_{2}$ \\
\hline \multicolumn{2}{|c|}{$\begin{array}{c}\mathrm{K}_{\mathrm{A}}, \mathrm{K}_{\mathrm{B}}, \mathrm{K}_{\mathrm{E}} \text { and } \mathrm{K}_{\mathrm{W}} \text { Adsorption equilibrium constant of fatty acid, alcohol, fatty acid ester and } \\
\text { water respectively (liter/mol.g cat.s) }\end{array}$} \\
\hline $\mathrm{K}_{\mathrm{s}}$ & Equilibrium surface reaction rate constant for esterification reaction (liter/mol) \\
\hline$k_{\mathrm{s}}$ & Surface reaction rate constant (liter/mol.gcat.s) \\
\hline$k_{1}$ & Forward reaction second order rate constant $\left(\mathrm{L} \mathrm{mol}^{-1} \mathrm{~h}^{-1}\right)$ \\
\hline$k_{2}$ & Backward reaction second order rate constant $\left(\mathrm{L} \mathrm{mol}^{-1} \mathrm{~h}^{-1}\right)$ \\
\hline M & $\mathrm{C}_{\mathrm{BO}} / \mathrm{C}_{\mathrm{AO}}=$ Molar ratio \\
\hline $\mathrm{N}$ & Number of experimental data \\
\hline $\mathrm{P}$ & Number of parameters to be determined \\
\hline $\mathrm{R}$ & Gas Law Constant $(8.314 \mathrm{~kJ} / \mathrm{mol} . \mathrm{K})$ \\
\hline$\left(-r_{s}\right)^{\prime}$ & $\begin{array}{l}\text { Rate of surface reaction in terms of palmitic acid consumption (mol/liter. } \\
\text { gcat.s) }\end{array}$ \\
\hline$\left(\mathrm{r}_{\mathrm{exp}}\right)^{\prime}$ & Experimental rate of reaction, mol/litre.gcat.s \\
\hline$\left(\mathrm{r}_{\mathrm{cal}}\right)^{\prime}$ & Calculated rate of reaction, mol/litre.gcat.s \\
\hline $\mathrm{T}$ & Temperature, $\mathrm{K}$ \\
\hline $\mathrm{X}_{A}$ & $1-\left(\mathrm{C}_{\mathrm{A}} / \mathrm{C}_{\mathrm{Ao}}\right)$, dimensionless \\
\hline$\sigma^{2}$ & Variance \\
\hline
\end{tabular}

\section{REFERENCES}

[1] S.H. Fogler, "Elements of Chemical Engineering, 3rd edn." Prentice Hall, New Jersey (USA), 1999.

[2] S. Goto, T. Tagawa and A. Yusoff, "Kinetics of the Esterification of Palmitic Acid with Isobutyl Alcohol." International Journal of Chemical Kinetics, 23, pp. 17-26, 1991.

[3] O. Levenspiel, "Chemical Reaction Engineering, 3rd edn." Wiley-Interscience Publication, New York, 2002.

[4] R.H. Perry and D. Green, "Perry's Chemical Engineer's Handbook, 6th edn," McGraw Hill, New York (USA). 
[5] C. Vieville, Z. Moulooungui and A. Gaset, "Esterification of Oleic Acid by Methanol Catalyzed by p-Toluenesulfonic Acid and the Cation-exchange Resins K2411 and K1481 in Supercritical Carbon Dioxide.” Ind. Eng. Chem. Res. 32, pp. 2065-2068, 1993.

[6] A. Chakrabarti and M.M. Sharma, "Cation Ion Exchange Resin as Catalyst." React. Polym., 20, pp. 1-45, 1993.

[7] Y. Fuchigami, "Hydrolysis of Methyl Acetate in Distillation Column Packed with Reactive Packing of Ion Exchange Resin.” J. Chem. Eng. Japan, 23, pp. 354-358, 1990.

[8] J. Savkovic-Stevanovic, M. Misic-Vukovic, G. Boncic-Caricic, B. Trisovic and S. Jezdic, "Reactive Distillation with Ion Exchanger." Sep. Sci. Technol., 27, pp. 613- 630, 1992.

[9] K. Tanabbe, M. Misono, Y. Ono, and H. Hattori, "New Solid Acids and Bases." Kodansha Ltd., Tokyo and Elsevier Science Publishers B.V., Amsterdam, 1989.

[10] M. Thomas, Sir John, “Solid Acid Catalysts.” Sci. Am., 266(4), pp. 112-118, 1992.

[11] R. Roy, and S. Bhatia, "Kinetics of Esterification of Benzyl Alcohol with Acetic Acid Catalyzed by Cation-Exchange Resin (Amberlyst 15)." J. Chem. Tech. Bioteknol., 37, pp. 110, 1987.

[12] H.J. Bart, J. Reidetschager, K. Schatka, and A. Lehmann, "Kinetics of Esterification of Levulinic Acid with n-Butanol by Homogenenous Catalysis." Ind. Eng. Chem. Res., 33, pp. 21-25, 1994.

[13] G.F. Froment, and K.B. Bischoff, "Chemical Reaction Analysis and Design, 2nd ed." JohnWiley and Sons, New York, 1979.

[14] U.R. Unnithan, and K.K. Tiwari, "Kinetics of Esterification of Oleic Acid and Mixtures of Fatty Acids with Methanol using Sulfuric Acid and p-Toluene sulfonic Acid as Catalyst." Indian Journal of Technology, 25, pp. 477-479, 1987.

\section{BIOGRAPHIES}

Amelia Qarina Yaakob obtained her B. Sc. degree in Chemical Engineering from University Science Malaysia in 2004. She is currently working with Jabatan Penerbangan Awam in Putrajaya as a technical engineer.

Prof. Subhash Bhatia joined the School of Chemical Engineering, University Science Malaysia, Engineering Campus, in 1995. He was full Professor in the Department of Chemical Engineering, Indian Institute of Technology, Kanpur (India). Prof. Bhatia was a visiting professor at the University of Queensland, Australia from 1998-1989 and 1994-1995. His research interests are Zeolite catalysis, chemical reaction engineering and environmental catalysis. He has written a book on Zeolite Catalysis that was published by CRC Press, USA and has published more than 150 papers in national and international refereed journals. 